\title{
DEBATES
}

\section{Contra el fraude populista: marxismo, sociedad civil y Estado en la filosofia de Antonio Gramsci}

\author{
Against the populist fraud: Marxism, civil society and State in \\ Antonio Gramsci's philosophy
}

\section{Alejandro Sánchez Berrocal}

\section{Resumen}

Se realiza una crítica de la lectura populista de algunos de los puntos centrales de la filosofía de Antonio Gramsci, concretamente aquellos que afectan a su teoría marxista sobre la sociedad civil y el Estado. La metodología empleada consiste en el análisis, comparación e interpretación de algunas obras de autores como Marx, Gramsci, Laclau y Mouffe para mostrar cómo el indiscutible interés por el autor italiano en el panorama político de nuestros días ha fomentado, sin embargo, ciertas visiones "posmodernas" sobre su pensamiento (en España continuadas por Errejón e Iglesias, sobre todo) que lo deforman y falsifican hasta dejarlo irreconocible.

\section{Palabras clave}

Populismo; Marxismo; Gramsci; Sociedad Civil; Estado.

\section{Abstract}

This article offers a critique of the populist reading of some of the central points of Antonio Gramsci's philosophy, specifically those that affect his Marxist theory on civil society and the State. The methodology used consists in the analysis, comparison and interpretation of some works by authors such as Marx, Gramsci, Laclau and Mouffe to show how the undisputed interest in the Italian author inside the political panorama of our days has, nonetheless, fostered certain "postmodern" visions about his thought (in Spain by Errejón and Iglesias, above all) that distort and falsify it until making it unrecognizable.

\section{Keywords}

Populism; Marxism; Gramsci; Civil Society; State. 


\section{La teoria populista es un antimarxismo ${ }^{1}$}

Antonio Gramsci (1891-1937) fue un hombre que dio su vida por la idea comunista. Gran parte de su actividad política e intelectual consiste en una discusión fecunda e inteligente con las principales aportaciones de Karl Marx, las cuales fue capaz de enriquecer y prolongar en un conjunto de reflexiones tan innovadoras como influyentes en la historia de la filosofía, desde las primeras décadas del siglo XX hasta nuestros días. Gramsci, si se excusa la obviedad, era un filósofo marxista. El problema es que esto no resulta ser tan obvio para algunos autores, los cuales asumen tesis antimarxistas y, al mismo tiempo, recuren a Gramsci para disimular la estrechez conceptual de sus teorías².

Para poder arrojar luz sobre esta cuestión, antes de presentar el apartado sobre la sociedad civil y el Estado quisiéramos anticipar algunas ideas sobre una de las obras fundamentales para el populismo: "Hegemonía y estrategia socialista" (1987), de Ernesto Laclau y Chantal Mouffe. Esta obra se propone una "subversión de las categorías del marxismo clásico" teniendo en cuenta "el surgimiento de la "hegemonía" como una nueva lógica de constitución de lo social que recompone, a un nivel distinto del postulado por la tradición marxista, los fragmentos sociales, dislocados y dispersos por esa igualdad del desarrollo" (LACLAU y MOUFFE, 1987, p. 8). Esta "lógica de lo social" no es un complemento de la teoría marxista, tampoco una consecuencia, sino precisamente aquello que la haría incompatible con sus premisas más fundamentales. "Aquí la referencia a Gramsci, si bien parcialmente crítica, es capital” (LACLAU y MOUFFE, 1987, p. 4). Tenemos, así, un punto de partida que puede parecer paradójico: un concepto, hegemonía, nacido en el interior de la teoría marxista (Lenin es la referencia principal en este sentido) resulta ser la clave para desecharla.

Merece la pena detenernos en esta cuestión para intentar matizar, si fuera posible, su carácter contraintuitivo. ¿Cuál es exactamente el papel que ocupa Gramsci

\footnotetext{
${ }^{1}$ La elaboración del presente artículo ha sido posible gracias a la financiación del Ministerio de Educación, Cultura y Deporte a través de un contrato FPU (FPU17/03632) y se inscribe en el marco del proyecto de investigación "El desván de la razón: Cultivo de pasiones, identidades éticas y sociedades digitales" (FFI2017.82272-: PAIDESOC).

2 En un excelente capítulo de libro, Santiago Armesilla (2016) trata algunas de estas cuestiones, enfatizando en la imposibilidad de reducir el pensamiento marxista de Gramsci a la mera crítica lingüístico-cultural. Concretamente sobre las inconsistencias teóricas de Laclau y Mouffe a propósito del concepto gramsciano de hegemonía han escrito autores como Boron y Cuéllar (1983), Boothman (2002), Shandro (2014) y Garrido Fernández (2018), entre otros.
} 
en todo esto? Laclau y Mouffe $(1987$, p. 8) lo tienen claro: "el pensamiento de Gramsci es sólo un momento transicional en la deconstrucción del paradigma político esencialista del marxismo clásico". Existen aquí dos cuestiones que quisiéramos valorar. Por un lado, se considera que el filósofo italiano no es, en sentido estricto, alguien que ha continuado y profundizado algunos de los principios fundamentales del marxismo, sino que más bien ha operado como un deconstructor de los mismos que, sin embargo, se ha quedado "a medio camino" en su labor. Por otro lado, se habla de un "paradigma político esencialista del marxismo clásico". Veamos en qué consiste esto último para intentar responder a la otra cuestión.

Es habitual enmarcar a autores como Ernesto Laclau y Chantal Mouffe en la estela de lo que se viene llamando el pensamiento "postmarxista". Ellos mismos lo reconocen cuando afirman que "hoy nos encontramos ubicados en un terreno claramente posmarxista” (LACLAU y MOUFFE, 1987, p. 4). La tesis crítica que quisiéramos esbozar brevemente es que esto solo es cierto en la medida en que Laclau y Mouffe sean "posmarxistas" en cuanto han escrito cronológicamente después de Marx, pero no porque continúen o desarrollen sus premisas fundamentales, ya que en este sentido son abiertamente antimarxistas ${ }^{3}$. Para sostener esta idea es preciso conocer qué caracterización realizan del "marxismo clásico". No es este el lugar para ofrecer una panorámica general y exhaustiva de la cuestión, pero sí, al menos, para precisar ciertos malentendidos. El siguiente fragmento donde se recogen "las tres tesis básicas del esquema marxista” según Laclau y Mouffe es crucial, por lo que nos permitimos transcribirlo completo para proceder a su crítica:

La condición del carácter endógeno de las leyes de la economía, mediante la tesis de la neutralidad de las fuerzas productivas. La condición de la unidad a nivel económico de los agentes sociales, mediante la tesis de la homogeneización y pauperización crecientes de la clase obrera. La condición de que las relaciones de producción sean el locus de "intereses históricos", que trascienden la esfera de la economía, mediante la tesis de que la clase obrera tiene un interés fundamental en el socialismo. Intentaremos, pues, mostrar que estas tres tesis son falsas (LACLAU y MOUFFE, 1987, p. 91).

El problema es que estas tesis, así enunciadas, no se corresponden en absoluto con ningunas de las ideas que haya sostenido la tradición marxista, de Marx a

\footnotetext{
${ }^{3}$ Esta cuestión remite a algunas críticas, ya clásicas, de autores como Geras (1987 y 1988), Mouzelis (1988), Rustin (1988) y Boron (1996).
} 
Gramsci, pasando por Engels y Lenin. Esta cuestión no tiene que ver con un error de lectura, sino con un auténtico ejercicio de deformación intelectual y simplificación de la filosofía de Marx que merece ser criticado (es importante señalar, por cierto, que en las siguientes páginas que comentaremos, Laclau y Mouffe jamás citan a Marx, sino a autores que hablan de Marx, como Bowles, Gintis o Cohen). Veamos en qué consisten estas tesis.

1. La tesis de la neutralidad de las fuerzas productivas. Según Laclau y Mouffe (1987, p. 91-92), para el marxismo

es posible concebir la economía como una mecánica de la sociedad, que actúa sobre los fenómenos objetivos independientemente de la acción de los hombres. Ahora bien, para que esta ley general del desarrollo de las fuerzas productivas tenga plena vigencia, es necesario que todos los elementos intervinientes en el proceso productivo estén sometidos a sus determinaciones; para esto el marxismo debió recurrir a una ficción: el considerar a la fuerza de trabajo como una mercancía. Sam Bowles y Herbert Gintis han mostrado cómo esta ficción va a hacer al marxismo ciego a toda una serie de características de la fuerza de trabajo en tanto que elemento del proceso de producción capitalista (LACLAU y MOUFFE, 1987, p. 91-92).

En este fragmento Laclau y Mouffe incurren en una confusión que lastra toda su argumentación posterior y no es otra que atribuirle al marxismo la idea de que la fuerza de trabajo es una mercancía como cualquier otra ${ }^{4}$. A partir de aquí, Marx

\footnotetext{
4 Afirmación completamente equivocada si tenemos en cuenta que la fuerza de trabajo es una mercancía peculiarísima en cuanto está “incorporada”, por así decirlo, en los trabajadores y en un determinado plexo de relaciones sociales. Precisamente esto es lo que le permite a Marx hablar del "fetichismo" de la mercancía, y su carácter "fetichista" implica que la mercancía no es únicamente mercancía. Contra la visión de Laclau y Mouffe, quienes consideran que Marx (2007, p. 227-230) teorizó sobre la fuerza de trabajo como una mercancía entre otras al margen de relaciones de dominación, recordamos cómo el filósofo alemán llama la atención sobre el elemento histórico y moral que implica tal noción: "La naturaleza no produce, de un lado, poseedores de dinero o de mercancías y, de otro, meros poseedores de sus fuerzas personales de trabajo. Esta relación no es obra de la historia natural ni tampoco es una relación social, común a todos los períodos de la historia [...] Para modificar la naturaleza humana general de manera que alcance habilidad y destreza en una rama determinada del trabajo, para que se convierta en fuerza de trabajo [...] se requiere una determinada formación o educación, que, a su vez, cuesta una suma mayor o menor de equivalentes de mercancías”.
} 
habría estado ciego para comprender cómo el capitalismo ejerce una dominación que busca controlar el proceso de trabajo y a los obreros implicados en él. Por el contrario, el filósofo alemán hablaría del "desarrollo de las fuerzas productivas como un proceso neutro" (LACLAU y MOUFFE, 1987, p. 92). Nada más lejos de la realidad, pues en buena medida el libro primero de "El Capital" va destinado a desmentir esta idea en su totalidad: el carácter dual del proceso de producción capitalista (fabricación de un producto y valorización del capital) y la necesidad de un control explícito (político, social, disciplinario...) del mismo son dos muestras de ello. El hecho de que la fuerza de trabajo sea una mercancía peculiar (véase la nota al pie n. 4) que requiere de una violencia histórica de una clase sobre la otra, también. Igualmente ilustrativo puede resultar el siguiente pasaje: "Lo mismo que un ejército militar, la masa de obreros que trabajan juntos bajo el mando del mismo capital necesita oficiales industriales (directores, gerentes) y suboficiales (inspectores, forement, overlookers, contre-maîtres)" (MARX, 2007, p. 30)5. En realidad, y aunque pueda parecer sorprendente, Laclau y Mouffe le atribuyen a Marx aquello que él ya criticó de la actitud apologética de la economía burguesa, ya que el proceso de trabajo no se determina exclusivamente por un "proceso neutro" que emane de las propias exigencias del sistema de producción, sino por el antagonismo que implican las relaciones de dominación y resistencia entre capitalistas y proletarios. Así lo expresa el mismo Marx cuando dice:

La dirección del capitalista no es solamente una función de la explotación de un proceso de trabajo social y, por tanto, condicionada por el inevitable antagonismo entre el explotador y peculiar de él; es, al propio tiempo, una función de la explotación de un proceso de trabajo social y, por tanto, condicionada por el inevitable antagonismo entre el explotador y la materia prima de su explotación (MARX, 2007, p. 29).

Laclau y Mouffe incurren, por tanto, en el peor de los fetichismos, al errar en su lectura de Marx y ver en él un teórico de la fuerza de trabajo como una mercancía entre otras.

5 Otro ejemplo de cómo Marx y Engels (2010, p. 47) entretejen relaciones de dominación de naturaleza social y política con otras de tipo económico: "La burguesía va eliminando progresivamente la dispersión de los medios de producción, de la propiedad y de la población. Ha aglomerado la población, centralizado los medios de producción, concentrado la propiedad en pocas manos. Consecuencia necesaria de esto ha sido la centralización política”. ¡Nada más lejos de la economía como esa "fuerza todopoderosa" y "neutra" que Laclau ve en Marx! 
Los ejemplos son abundantísimos, pero esta muestra sirve para hacer ver que en Marx la economía no es una "fuerza todopoderosa, que parece operar sin trabas, como si las fuerzas económicas a disposición del capital no permitieran a la clase obrera resistir e influir el curso del desarrollo" (LACLAU y MOUFFE, 1987, p. 93). Esta es una crítica falsa, deformada y que da cuenta de una lectura (si es que se ha producido) profundamente distorsionada de Marx. Por ello no deja de extrañar que Laclau y Mouffe (1987, p. 93) anuncien como un descubrimiento lo que hemos visto estaba presente, de diferentes maneras, en Marx: "la crítica a la concepción de la fuerza de trabajo como mercancía cuyo valor de uso sería el trabajo nos permite entender la necesidad del capital de controlar el proceso de trabajo". Pero para entender "la necesidad del capital de controlar el proceso de trabajo" no era necesario hacerle decir a Marx lo que jamás ha dicho, sino leerlo con un mínimo de honestidad intelectual. Y esto es así porque, como hemos tenido ocasión de mostrar, el filósofo alemán jamás optó por separar los procesos de producción, la economía en general, de las relaciones sociales, más bien todo lo contrario, porque ello es precisamente el núcleo del pensamiento marxista que permite postular una serie de consecuencias relacionadas con los antagonismos del sistema capitalista y la lucha de clases.

2. La tesis de la homogeneización y pauperización crecientes de la clase obrera que sería "condición de la unidad a nivel económico de los agentes sociales", como vimos más arriba, es el segundo supuesto marxista que Laclau y Mouffe quieren refutar. Pero ambos autores parten de una premisa equivocada para hacerlo, aquella que es deudora de la primera tesis: "la economía difícilmente podría constituir sujetos unificados a través de una lógica única que ella misma no posee" (LACLAU y MOUFFE, 1987, p. 95). Ya hemos visto que la economía “por sí misma”, como una "fuerza neutral" no existe en Marx, y que ella es siempre economía política, esto es, economía atravesada por relaciones de dominación o lucha de clases. En este caso el argumento de ambos autores es que la clase obrera está "constituida por una pluralidad de posiciones de sujeto débilmente integradas y en muchos casos contradictorias", por lo que, continúan:

Aquí la alternativa es clara: o bien se tiene una teoría de la historia según la cual esa pluralidad contradictoria sería eliminada y a la hora del quiliasmo proletario emergerá una clase obrera absolutamente unitaria y transparente respecto a sí misma - en cuyo caso sus "intereses objetivos" pueden determinarse desde un comienzo -, o bien dicha teoría es abandonada, en cuyo caso no hay ningún fundamento para privilegiar 
ciertas posiciones de sujeto antes que otras en la determinación de los intereses "objetivos" del agente como un todo - en verdad, esta última noción pasa a carecer de sentido -. Si se quiere avanzar en la determinación de los antagonismos sociales lo que hay que hacer, por tanto, es analizar esta pluralidad de posiciones diversas y en muchos casos contradictorias, y abandonar la idea de un agente perfectamente unificado y homogéneo tal como la "clase obrera" del discurso clásico (LACLAU y MOUFFE, 1987, p. 100).

Lo que este pasaje nos muestra es la impugnación en su totalidad de la idea marxista de la lucha de clases y, en realidad, de la existencia misma de clases. Laclau y Mouffe pueden sostener que la "clase obrera" pierde su estatuto privilegiado porque antes han afirmado que su misma existencia no es la consecuencia del desarrollo de las contradicciones del capitalismo que es, por el contrario, la postura de Marx. Perdido su estatuto privilegiado, perdido, incluso, su calidad de agente en cuanto "todo", el proletariado queda libre para unirse a otros agentes sociales de manera contingente en un escenario de "posiciones diversas y contradictorias". En realidad, la argumentación es un ataque frontal a uno de los principios fundamentales del materialismo histórico. Veamos cómo lo resumen Laclau y Mouffe (1987, p. 100): "no es posible deducir lógicamente intereses fundamentales en el socialismo a partir de determinadas posiciones en el proceso económico". Como de manera aguda ha visto Meiksins Wood (1986, p. 60-61), este tipo de razonamientos que sostienen ambos autores no puede significar más que las condiciones de explotación capitalista dejan de ser un factor determinante en las experiencias y modos de vida de la clase trabajadora, porque existen otras condiciones y contingencias, "diversas y contradictorias", que afectan a su situación. De modo que, afirma la autora:

The implication is that workers are no more affected by capitalist exploitation than are any other human beings who are not themselves the direct objets of exploitation. This also implies that capitalists derive no fundamental advantage from the exploitation of workers, that the workers derive no fundamental disadvantage from their exploitation by capital, that workers would derive no fundamental advantage from ceasing to be exploited, that the condition of being exploited does not entail an "interest" in the cessation of class explotation, that the relations between capital and labour have no fundamental consequences for the whole structure of social and political power, and that the conflicting interests between capital and labour are all in the eye of the beholder (MEIKSINS WOOD, 1986, p. 61). 
Es decir, que absolutamente todas las premisas que se derivan de la idea de "lucha de clases", así como algunos principios básicos del materialismo histórico, quedan directamente negados por los argumentos de Laclau y Mouffe. Cuando Marx le escribe a J. Weydemeyer, el 5 de marzo de 1852, que "en lo que a mí respecta, no ostento el título de descubridor de la existencia de las clases en la sociedad moderna, ni tampoco de la lucha entre ellas" y que, entre otras cosas, lo nuevo que intentó demostrar fue "que la existencia de las clases está vinculada únicamente a fases particulares, históricas, del desarrollo de la producción” (WEYDEMEYER, 1852, s/p apud HARNECKER, 2007, p. 222), no estaría sosteniendo una concepción "esencialista" ni "determinista" de la clase obrera como algo perfectamente "unitario", sino precisamente su radical historicidad e inserción en un determinado plexo de relaciones productivas y, por tanto, sociales: sus "intereses objetivos" no pueden decidirse de antemano porque ellos dependen del desarrollo de la lucha entre clase obrera y capitalistas, entre otros factores. "La lucha entre el capitalista y el obrero asalariado se inicia con la propia relación capitalista” afirma Marx (2007, p. 153). Y si la clase obrera adquiere en el marxismo el aspecto de "privilegiada" no es porque neutralice una "pluralidad contradictoria", como sostiene Laclau, sino porque en la época del capitalismo industrial es capaz de acogerla en sí. No es tanto el proletariado una clase entre otras, en ese momento histórico, como la clase por excelencia, y ello no por una visión "determinista" y "esencialista", sino como consecuencia del desarrollo del capitalismo:

Las clases intermedias hasta ahora existentes, pequeños industriales, comerciantes y rentistas, artesanos y campesinos, todas estas clases caen en el proletariado, ya sea debido a que su pequeño capital no basta para lanzarse a la gran empresa y sucumbe en la competencia con los capitalistas mayores, ya sea debido a que su habilidad ha quedado devaluada por nuevos métodos de producción. De manera que el proletariado se recluta de todas las clases de la población (MARX y ENGELS, 2010, p. 51).

$\mathrm{Y}$ es que cuando Laclau y Mouffe obligan al lector a decidirse entre una "teoría de la historia" de acuerdo con las falsificaciones del marxismo que postulan o abandonarla en favor de una heterogeneidad radical donde ninguna posición de sujeto es privilegiada no hacen solo negar el vínculo entre desarrollo capitalista y 
proletariado y la consecuente lucha de clases entre explotadores y explotados, sino también niegan la importancia misma de la historia en el devenir de los procesos sociales ${ }^{6}$. De nuevo recurrimos a Meiksins Wood, quien critica esta postura de ambos autores del siguiente modo:

What it effectively means [el hecho de que no haya concepción de la importancia histórica en los procesos sociales en Laclau y Mouffe] is that, where there is no simple, absolute, mechanical, unnilinear, and noncontradictory determination, there is no determinacy, no relationship, no casualty at all. There are no historical conditions, connections, limits, possibilites. There are only arbitrary juxtapositions, "conjunctures" and contingences. If anythings holds the discrete and isolated fragments of reality together, it is only the logic of discourse (MEIKSINS WOOD, 1986, p. 62).

La supresión de toda condición histórica, de posibles vínculos entre causas y consecuencias, de determinaciones introducidas por el trabajo de la lucha de clases a lo largo de la historia en favor del "discurso", es, sin duda, otro punto fundamental del antimarxismo de Laclau y Mouffle. Resulta, de nuevo, una de las grandes renuncias que estos autores hacen de la herencia de Marx, y un ataque frontal a una de las principales consecuencias de la concepción de la historia que expuso en "La ideología alemana":

En el desarrollo de las fuerzas productivas, se llega a una fase en la que surgen fuerzas productivas y medios de intercambio que, bajo las relaciones existentes, solo pueden ser fuente de males, que no son ya tales fuerzas de producción, sino más bien fuerzas de destrucción (maquinaria y dinero); y, lo que está íntimamente relacionado con ello, surge una clase condenada a soportar todos los inconvenientes de la sociedad sin gozar de sus ventajas, que se ve expulsada de la sociedad y obligada a colocarse en la más resuelta contraposición a todas las demás clases; una clase que forma la mayoría de todos los miembros de la sociedad y de la que nace la conciencia de que es necesaria una revolución radical, la conciencia comunista, conciencia que, naturalmente, puede llegar a

\footnotetext{
${ }^{6}$ Laclau procede, como en otras ocasiones, planteando una "falsa" dicotomía que muestra sus escasas capacidades para el pensamiento dialéctico: o el supuesto determinismo histórico o la contingencia. Pero la alternativa está ya, de antemano, trucada, porque la primera opción no se corresponde con las tesis marxistas. Siguen vigentes las palabras de Marx (1877) al director del Otiechéstvennie Zapiski a propósito precisamente de la imposibilidad de una teoría histórico-filosófica general.
} 
formarse también entre las otras clases, al contemplar la posición en que se halla colocada esta (MARX y ENGELS, 2014, p. 60-61. El destaque es propio).

3. Para Laclau y Mouffe, como ya expusimos, existía una tercera idea marxista "falsa", que consiste en que "las relaciones de producción" son el locus de "intereses históricos", lo que es posible afirmar gracias "la tesis de que la clase obrera tiene un interés fundamental en el socialismo". El hecho de que "la clase obrera" tenga "un interés fundamental en el socialismo" no es un dato a priori ni mucho menos un supuesto para el marxismo, pues de lo contrario no tendrían sentido las reflexiones a propósito de la ideología o la "conciencia de clase". No profundizaremos más en las inconsistencias teóricas de Laclau y Mouffe a propósito del marxismo. Remitimos, en este sentido, a algunos de los artículos recogidos en la bibliografía sobre la cuestión de la "la hegemonía" y el posmarxismo. Lo que quisiéramos mencionar brevemente, para concluir esta sección, es cómo ambos autores sustituyen la filosofía de Marx por una teoría idealista y, por ello, antimarxista.

Como hemos visto, en el análisis de Laclau y Mouffe de los principios "marxistas clásicos" se han rechazado buena parte de las tesis fundamentales que alimentan esta filosofía: primacía de la clase obrera, vinculación entre desarrollo del capitalismo y lucha de clases, dominación en un plano "social" y "político" de relaciones de producción etc. El gran paso de ambos autores consiste, de hecho, en negar la existencia de condiciones materiales que sucedan "al margen" o "de espaldas" a sus agentes, como sucedería en el marxismo, ya que "nuestro análisis rechaza la distinción entre prácticas discursivas y no discursivas" (LACLAU y MOUFFE, 1987, p. 121). Es decir, en la ontología social del populismo no existe un discurso sobre las condiciones de clase, la coyuntura económica o el desarrollo de las contradicciones del capitalismo, o no existe al menos considerando estos elementos en su eficacia material al margen de cualquier emisión lingüística sobre los mismos. Allí donde alguien podría ver fenómenos sociales que se escapan al discurso, Laclau y Mouffe responden:

Si se analizan los presuntos complejos no-discursivos - instituciones, técnicas, organización productiva, etc. - solamente nos encontraremos con formas más o menos complejas de relaciones diferenciales entre objetos, que no brotan de una necesidad exterior al sistema que las estructura y que sólo es posible concebir, por tanto, como articulaciones discursivas (LACLAU y MOUFFE, 1987, p. 122). 
Laclau y Mouffe no niegan la objetividad, sino que consideran el discurso como la instancia privilegiada para representarla y producirla. Todos los parámetros quedan cancelados, cualquier relación económica, social, religiosa, cultural, etc., es de antemano inabarcable si no queda atrapada por la labor del discurso. Hasta una matanza o un genocidio son la consecuencia de un determinado discurso que se ha "extremado": "la "limpieza" de poblaciones enteras constituye siempre una posibilidad latente cuando la construcción discursiva de la comunidad procede según líneas puramente étnicas" (LACLAU, 2005, p. 244). Proletarios, capitalistas, explotados y explotadores, todos pueden participar por igual en el gelatinoso médium del discurso, que se asegura dejar a salvo de la historia y las condiciones materiales a sus agentes sociales y relaciones, siempre diferentes, siempre heterogéneos, siempre contingentes, articulados alrededor de uno u otro líder que les asegure la consistencia, la misma que desaparece al esfumarse aquel. Como señala Antonio Rivera García (2015, p. 48), "se comprende así que algunos denuncien la impostura de Laclau, y digan que ha puesto en circulación una moneda falsa, el populismo". Una moneda antimarxista, añadimos nosotros.

\section{Sociedad civil y Estado en la filosofia de Gramsci}

Llegados a este punto hemos visto cómo la teoría del populismo impugna la filosofía marxista mediante falsificaciones y distorsiones. Ahora quisiéramos mostrar cómo incorpora en su aparato conceptual ciertas ideas de Gramsci cuya valoración de ninguna manera resiste un cotejo con las fuentes textuales del filósofo italiano. La hipótesis que sostenemos es que los teóricos del populismo español pretenden aplicar las nociones de Gramsci a una sociedad civil que, en realidad, interpretan desde la óptica del liberalismo. Veamos cómo es esto.

Hay un artículo periodístico de Pablo Iglesias (2015) que comienza del siguiente modo: "en los párrafos más legendarios [no especifica cuáles] de sus 'Quaderni del carcere', Antonio Gramsci reflexionaba sobre las estrategias de guerra de la I Guerra Mundial, posición y maniobra, para entender la política en Occidente”. También Errejón (2012; 2013; 2016a; 2017 y 2018) ha usado frecuentemente esta idea. A juicio de ambos, el momento del "asalto" debe dar paso al de las "trincheras" en la sociedad civil, donde se produzca un trabajo lento y complejo de creación de nuevos consensos y difusión de las ideas populistas. En primer lugar, veamos los, en palabras de Iglesias, "legendarios párrafos" de Gramsci: 
Me parece que Ilich [Lenin] había comprendido que estaba dándose una mutación de la guerra de maniobras, aplicada victoriosamente en Oriente en el 17, a la guerra de posiciones, que era la única posible en Occidente, donde, como observa Krasnov, en un breve espacio de tiempo los ejércitos podían acumular abundantes cantidades de municiones, donde los cuadros sociales eran, por sí mismos, todavía capaces de convertirse en trincheras bien equipadas [...] En Oriente el Estado era todo, la sociedad civil era embrionaria y gelatinosa; en Occidente entre el Estado y la sociedad civil existía un sutil equilibrio que aseguraba una sociedad civil fuerte y robusta incluso en los momentos de temblor del Estado. El Estado era solo una trinchera avanzada, detrás de la cual existía una vigorosa cadena de fortalezas y casamatas (GRAMSCI, 2014, p. 886)7

La metáfora militar, adquiere, en este otro pasaje, un significado eminentemente político:

La estructura "de masas" de las democracias contemporáneas, ya sea en cuanto organizaciones estatales o como conjunto de asociaciones en la vida civil constituyen para el arte de la política las "trincheras" y fortificaciones permanentes del frente de guerra de posiciones: de este modo el elemento de movimiento que antes era "toda la guerra" ahora se vuelve "parcial" (GRAMSCI, 2014, p. 1567).

La interpretación de este tipo de fragmentos ha permitido que algunos teóricos del populismo crean ver en Gramsci un “teórico del poder” en las sociedades occidentales que abre una "vía democrática" al ejercicio del poder estatal desde las posiciones de la sociedad civil. Sin embargo, hay dos errores fundamentales en la lectura de Errejón e Iglesias de este fenómeno: la escisión de la sociedad civil y el Estado en dos momentos orgánicamente diferentes y la creencia en que la "guerra de posiciones" es un trabajo estrictamente superestructural. Comprobemos inmediatamente ambos errores.

El constructivismo sin límites de Errejón (2016b) hace que sea difícil encontrar una definición de sociedad civil en sus textos: "la "sociedad civil" designa más bien hoy un lugar aún por articular, a la vez que permea un partido como el nuestro, antes que un ente homogéneo cuya representación agotan las organizaciones

\footnotetext{
${ }^{7}$ La traducción al español de todas las citas de ediciones extranjeras es siempre nuestra. Las referencias originales pueden ser consultadas en el apartado bibliográfico final.
} 
ya existentes". Por fortuna, recientemente ha desvelado el secreto en que consiste la esencia de la sociedad civil:

Los medios de comunicación, las series de ficción, los formatos de las redes sociales, el deporte, la música, las novelas o las asociaciones religiosas o de ocio, son esas instituciones de la sociedad civil que contribuyen a normalizar y fortificar un orden determinado (ERREJÓN, 2018, p. 17-18).

Estas serían las fortificaciones que se esconden detrás del Estado, al margen del cual "la política de la guerra de trincheras es la lucha por la hegemonía" (IGLESIAS, 2015, s/p). Con ello, tanto Errejón como Iglesias asumen que la hegemonía se desempeña como hegemonía cultural o intelectual en el ámbito de la sociedad civil, hipostasiando el momento del consenso y suprimiendo el de la coerción. Esto parece poco consecuente con la concepción “integral” de Estado, sociedad política y sociedad civil de Gramsci. Repasemos algunas de sus definiciones:

Es de señalar que en la noción general de Estado entran elementos que remiten a la sociedad civil (en este sentido, podría decirse que el Estado es igual a sociedad política + sociedad civil, esto es, hegemonía acorazada de coerción) (GRAMSCI, 2014, p. 763-764).

Si ciencia política significa ciencia del Estado y el Estado es un conjunto de actividades prácticas y teóricas a través del cual la clase dirigente no solo justifica y mantiene su dominio sino que además consigue obtener el consenso activo de los dominados [...] (GRAMSCI, 2014, p. 1763).

El Estado tiene y exige el consenso, pero también "educa" este consenso con las asociaciones políticas y sindicales, las cuales, sin embargo, son organismos privados, dejados a la iniciativa privada de la clase dominante. Hegel, en este sentido, supera ya, de este modo, el mero constitucionalismo y teoriza el Estado parlamentario con su régimen de partidos (GRAMSCI, 2014, p. 56).

El ejercicio "normal" de la hegemonía en el terreno ya clásico en que se mueven los regímenes parlamentarios está caracterizado por una combinación de fuerza y consenso que se equilibran, sin que la fuerza supere demasiado al consenso, por lo que más bien parece apoyarse en el consenso de la mayoría expresado, por así decirlo, en los órganos de la 
opinión pública (los cuales, precisamente por eso, resultan en ocasiones multiplicados de manera artificiosa) (GRAMSCI, 2014, p. 59).

Algunas consecuencias de estos fragmentos: la división entre sociedad civil y Estado corresponde a necesidades metodológicas, pero no se da como tal orgánicamente; la coerción y la fuerza, como aspecto del dominio, no son formas de ejercer el poder contrarias a la hegemonía, sino variantes de esta; la hegemonía no puede reducirse a prácticas culturales porque implica al "monopolio de la fuerza" estatal y, además, una trama de instituciones, como los partidos políticos o los sindicatos, que adquieren la "apariencia" de actuar al margen del Estado; los regímenes parlamentarios, las "democracias occidentales", no renuncian a la dominación por medio de la fuerza, sino que se sirven de la sociedad civil para ofrecer una imagen según la cual tal dominio es una cuestión de consenso.

Llegados a este punto, la distinción de Errejón e Iglesias entre "la guerra de trincheras" (sociedad civil), como lugar del consenso, y la "guerra de asalto" (Estado), como lugar de la fuerza, resulta errónea y depotencia el alcance político e integral de la concepción gramsciana del Estado. Al contraponer ambas esferas, se incurre en un error que César Ruiz Sanjuán ha diagnosticado, de manera magistral, como una despolitización del pensamiento de Gramsci y ello sucede

en tanto que supone la renuncia a la confrontación al nivel de las formas políticas del Estado y la ubicación de la lucha exclusivamente en el ámbito de la sociedad civil, con lo que Gramsci queda reducido al nivel de un "sindicalista cultural" y su teoría vaciada de verdadero sentido político y apta para ser apropiada por los estudios culturales más que por la filosofía política. El concepto de hegemonía se convierte así en una suerte de concepto "anti-político", que funciona como un dispositivo que diseńa una labor de zapa al nivel de la sociedad civil y que deja para las calendas griegas la lucha por el espacio político, que entretanto sigue siendo monopolio de la clase burguesa [...] Al ignorar el momento coercitivo de los regímenes parlamentarios y obviar que lo que efectivamente garantiza la hegemonía de la burguesía es la fuerza coactiva que detenta el Estado; esta estrategia [la de la izquierda socialdemócrata] sólo puede conducir a la adaptación de los movimientos de izquierdas al sistema político burgués (SANJUÁN, 2016, p. 9-10).

Olvidan Errejón e Iglesias, en su visión “culturalista” de Gramsci, el momento eminentemente político y, por supuesto, el militar, lo que hace 
irreconocible la teoría del filósofo italiano. Y es que resulta importante recordar que Gramsci jamás renunció a la dictadura del proletariado, ni tampoco al momento violento (en sentido amplio) que funda un nuevo orden. Como señala Rosengarten (1984-1985, p. 66) a propósito del filósofo italiano: "no conocemos ninguna ocasión donde él repudiara las medidas duras e incluso brutales que la joven República Soviética tomó contra sus reales y supuestos enemigos. El pensamiento político de Gramsci no debería ser arbitrariamente suavizado”. En una línea similar insiste Mandel cuando critica las interpretaciones reformistas y antirrevolucionarias de la herencia gramsciana:

Debe reconocerse que en la evolución de Gramsci, desde la fundación de "Ordine Nuovo" en 1919 hasta la elaboración de los "Cuadernos de la cárcel”, no existe la mínima evidencia de que Gramsci abandonara jamás la concepción de que la revolución socialista implica la destrucción de los aparatos estatales de la burguesía y la sustitución del régimen parlamentario y burgués por una democracia socialista basada en los consejos obreros libre y democráticamente elegidos (MANDEL, 1978, p. 229).

Más allá de estos temas, en el populismo español late, como hemos sugerido, una cierta idea de la sociedad civil que responde a un paradigma liberal, todo lo contrario de la concepción integral de Gramsci. De este modo, teóricos del populismo como Errejón e Iglesias están continuando un error que tiene su origen en un clásico artículo de Norberto Bobbio (1977, p. 159), donde se afirma que "en Gramsci, la sociedad civil no pertenece al momento de la estructura, sino al de la sobrestructura”. Según esta división, la sociedad civil quedaría desligada del momento estructural, esto es, económico, que sería dominio del Estado. Hemos tenido ocasión de mostrar cómo esta dicotomía es falsa y no se presenta como tal en el pensamiento de Gramsci desde el momento en que toda hegemonía es política y, sobre todo, económica, por lo que tiene una base material "estructural” (véase GRAMSCI, 2014, p. 461). Los siguientes pasajes ayudan a reforzar nuestra argumentación:

La impostura del movimiento liberal se basa en un error teórico cuyo origen práctico no es difícil de identificar: en la distinción entre sociedad política y sociedad civil, que pasa de ser una distinción metodológica para convertirse en una distinción orgánica. Así, se afirma que la actividad económica es propia de la sociedad civil y que el Estado no debe 
intervenir en su regulación. Pero en la realidad efectiva la sociedad civil y el Estado se identifican (GRAMSCI, 2014, p. 1589-1590).

Los liberales están de acuerdo con la concepción de un "Estado guardiánnocturno" [Stato-veilleur de nuit, en el original] y querrían que la iniciativa histórica fuese dejada a la sociedad civil y a las diversas fuerzas que por allí pululan, reservando al Estado el papel de guardián de "las reglas del juego" (GRAMSCI, 2014, p. 2302).

[...] El aparato hegemónico de un grupo social sobre el resto de la población (sociedad civil), base del Estado mismo estrictamente como aparato gobernativo-coercitivo [...] Por Estado debe entenderse el aparato gobernativo incluyendo el aparato "privado" de hegemonía o sociedad civil (GRAMSCI, 2014, p. 800-801).

Estos ejemplos podrían multiplicarse, pero detengámonos aquí. Llegados a este punto, resulta innegable la importancia del momento estructural, económico, como parte de la sociedad civil, así como su trabazón dialéctica y orgánica con la idea de Estado, algo que Bobbio rechaza al considerarla el lugar de la "superestructura", en lo que parecen coincidir Errejón e Iglesias, según su concepción de la "guerra de posiciones". Ahora bien, este tipo de distinciones esclerotizadas no se corresponden con el pensamiento vivo e integral de Gramsci, acaso porque los teóricos del populismo estén más interesados en "hacerse fuertes" en la sociedad civil y desplazar indefinidamente el horizonte de expectativas realmente transformador: "debemos cavar las trincheras de la sociedad civil" (AHORA PODEMOS, 2016, s/p). Pero como nos recuerda Domenico Losurdo $(2015$, s/p) en una entrevista: "la sociedad civil no es, necesariamente, el lugar de la emancipación”. Y es que ello afecta a un problema más profundo que interpela a todos los que intentamos hacer historia de la filosofía: ¿hasta qué punto es legítimo falsear una determinada teoría de acuerdo con ciertas estrategias ya no políticas, sino exclusivamente electoralistas? Quienes pretenden "bunkerizarse" en la sociedad civil y arroparse con conceptos gramscianos como el de "guerra de posiciones" no pueden considerarse "herederos" del filósofo italiano. Concluyamos con las siguientes palabras de Guido Liguori: 
El Estado es el terreno, el medio y el proceso en el que la lucha política se desarrolla necesariamente, y los actores principales de tal lucha son los que Gramsci llama "las clases fundamentales". Para Gramsci "hacerse Estado" (farsi Stato) es un momento ineludible de la lucha por la hegemonía (como lo es, también, disponer de un partido portador de una concepción del mundo precisa y alternativa). No hay espacio en - en Gramsci - para un "protagonismo de los intelectuales" o "de la sociedad civil”, no sin una consideración de estas cuestiones desconectada de las coordenadas de base (LIGUORI, 2004, p. 223).

\section{Conclusiones}

Este recorrido por la confrontación de las tesis posmarxistas (Laclau y Mouffe) con Antonio Gramsci nos permite presentar una serie de afirmaciones teóricas que, a nuestro juicio, actualiza y reanima el debate sobre los "usos" y "abusos" de su filosofía:

El así llamado "posmarxismo" de Laclau y Mouffe se basa en una operación conceptual, recurrente a lo largo de diferentes obras, que distorsiona el pensamiento marxista. El procedimiento, aunque hay otros, consiste en plantear diferentes dicotomías (esencialismo/contingencia, homogeneidad/pluralidad, ortodoxia/heterodoxia, etc...) en las cuales una de las opciones está ya, de antemano, trucada, de modo que el lector se vea empujado a apoyar, inmediatamente, la otra. Esta falsificación de las tesis marxistas trabaja, tal y como hemos comprobado en nuestro texto, sobre tres argumentos distintos (tesis de la neutralidad de las fuerzas productivas, de la homogeneización y la pauperización de la clase obrera como condición de su unidad y de las relaciones de producción como locus necesario de los intereses históricos) que, tal y como hemos demostrado a través de fuentes textuales, son falsos.

Por lo que respecta a Gramsci, es complicado admitir que su función en el curso de la historia del marxismo esté relacionada con una "deconstrucción" del mismo, más bien modifica, profundiza y enriquece aspectos que pertenecen al núcleo de la tradición marxista-leninista, los cuales, sin duda, son novedosos y relevantes, pero no "contrarios" al mismo: la cuestión de la "hegemonía" es paradigmática en este sentido.

En consecuencia, un criterio interpretativo adecuado, pero ni mucho menos el único, ha resultado ser la cuestión de la dialéctica entre sociedad civil y Estado. Al tratar en profundidad este tema, hemos visto cómo las interpretaciones populistas de Gramsci desfiguran la filosofía del italiano al postular dos principios que no solo no están en su pensamiento sino que lo contradicen: la separación orgánica, y no meramente 
metodológica, entre sociedad civil y Estado (y, por tanto, entre estructura y superestructura) y la cuestión del trabajo hegemónico exclusivamente al nivel de la sociedad civil. Ambas tesis son falsas y muestran cómo la ontología social de la teoría populista sigue siendo deudora, en buena medida, de la lógica liberal.

Alejandro Sánchez Berrocal é Doutorando em Filosofia na Universidade Nacional de Educação a Distância (UNED) e Instituto de Filosofia (IFS-CSIC). É contratado FPU do IFS-CSIC e da UNED. E-mail: alejandro.sanchez@cchs.csic.es.

\section{Referências}

AHORA PODEMOS. "Debemos cavar las trincheras de la sociedad civil. De eso depende nuestra supervivencia”, @Pablo_Iglesias_ \#Universidad de Podemos”, 25 de septiembre de 2016, 10:17. Disponible en: <https://twitter.com/ahorapodemos/status/780093974107328512>. Acceso en: 25/03/2019. Tuit.

ARMESILlA, Santiago. Comprendiendo a Podemos. In: BUENO SÁNCHEZ, Gustavo (Ed.). Podemos, ¿`comunismo, populismo o socialfascismo? Oviedo: Pentalfa, 2016, p. 89-155.

BOBBIO, Norberto. Gramsci y la concepción de la sociedad civil. In: FERNÁNDEZ BUEY, F. (Ed.). Actualidad del pensamiento político de Gramsci. Barcelona: Grijalbo, 1977, p. 150-177.

BOOTHMAN, Derek. The Sources of Gramsci's Concept of Hegemony. Rethingking Marxism, v. 20, n. 2, p. 201-215, 2008.

BORON, Atilio. ¿Posmarxismo? Crisis, recomposición o liquidación del marxismo en la obra de Ernesto Laclau. Revista Mexicana de Sociología, v. 58, n. 1, p. 17-42, 1996.

BORON, Atilio; CUÉLLAR, Óscar. Apuntes críticos sobre la concepción idealista de la hegemonía. Revista Mexicana de Sociología, v. 45, n. 4, p. 1143-1177, 1983.

ENGELS, Friedrich; MARX, Karl. La ideología alemana. Madrid: Akal, 2014. . Manifiesto Comunista. Madrid: Alianza Editorial, 2010.

ERREJÓN, Íñigo. Abriendo brecha: apuntes estratégicos tras las elecciones generales, $2016 \mathrm{a}$. Disponible en: <http://blogs.publico.es/dominiopublico/15529/abriendo-brecha-apuntesestrategicos-tras-las-elecciones-generales/>. Acesso en: 11 nov. 2018.

. Constituciones de transición y transformación del Estado en los procesos de cambio. Papeles de relaciones ecosociales y cambio global, v. 122, n. 1, p. 93-103, 2013.

Construir pueblo, 2016b. Disponible en: <https://www.lacircular.info/construir-pueblo/>. Acesso en: 11 nov. 2018. Artículo prensa digital. 
Desplegar las velas: un Podemos para gobernar, 2017. Disponible en: <https://www.estaticos.elmundo.es/documentos/2017/01/13/Errejon.pdf>. Acesso en: 11 nov. 2018. Documento de partido.

. En caso de duda, volver a Gramsci. In: LARRAURI, Maite; SÁNCHEZ, Dolores (Eds.). Contra el elitismo. Gramsci: manual de uso, Barcelona: Ariel, 2018, p. 8-19.

La lucha por la hegemonía durante el primer gobierno del MAS en Bolivia (2006-2009): un análisis discursivo. Tesis doctoral - Departamento de Ciencia Política y de la Administración III (Teorías y Formas Políticas y Geografía Humana) da Universidad Complutense de Madrid, 654f., 2012.

GARRIDO FERNÁNDEZ, Anxo. Memorias de un "perro muerto". Notas sobre el grupo Pasado y Presente. Res Publica, v. 21, n. 3, p. 615-631, 2018. Disponible en: <http://dx.doi.org/10.5209/RPUB.62446>. Acesso en: 11 nov. 2018.

GERAS, Norman. Ex-Marxism without substance: being a real reply to Laclau and Mouffe. New Left Review, v. 1, n. 169, p. 34-61, 1988.

GERAS, Norman. Post-Marxism? New Left Review, v. 1, n. 163, p. 40-82, 1987.

GRAMSCI, Antonio. Quaderni del carcere (4 vols.). Turín: Einaudi, 2014.

HARNECKER, Martha. Los conceptos elementales del materialismo histórico. Madrid: Siglo XXI, 2007.

IGLESIAS, Pablo. Guerra de trincheras y estrategia electoral, 2015. Disponible en: $<$ http://blogs.publico.es/pablo-iglesias/1025/guerra-de-trincheras-y-estrategia-electoral/>. Acesso en: 11 nov. 2018.

LACLAU, Ernesto; MOUFFE, Chantal. Hegemonía y estrategia socialista. Madrid: Siglo XXI, 1987.

LACLAU, Ernesto. La razón populista. México: Fondo de Cultura Económica, 2005.

LIGUORI, Guido. Stato-Società Civile. In: FROSINI, Fabio (Ed.). Le parole di Gramsci. Roma: Carocci Editore, 2004, p. 208-226.

LOSURDO, Domenico. La sociedad civil no es, necesariamente, el lugar de la emancipación (entrevistado por Santiago Armesilla), 2015. Disponible en: <http:/www.cronicapopular.es/2015/10/domenico-losurdo-la-sociedad-civil-no-es-necesariamenteel-lugar-de-la-emancipacion/>. Acesso en: 11 nov. 2018.

MANDEL, Ernest. From Stalinism to Eurocommunism. Londres: Verso, 1978.

MARX, Karl. Al director de Otiechéstvennie Zapiski. Disponível en: <https://www.marxists.org/espanol/m-e/cartas/m1877.htm>. Acceso en: 11 nov. 2018. Carta digitalizada.

MARX, Karl. El Capital. Madrid: Akal, 2007.

MEIKSINS WOOD, Ellen. The Retreat from Class. A New “True” Socialism. Londres: Verso, 1986.

MOUZELIS, Nicos. Marxism or Post-Marxism? New Left Review, v. 1, n. 167, p. 107-123, 1988.

RIVERA GARCÍA, Antonio. De la hegemonía al populismo: Enesto Laclau, la evolución de un «schmittiano antischmittiano». In: Castro Orellana, R. (ed.). Poshegemonía. El final de un paradigma de la filosofía política en América Latina, Madrid: Biblioteca Nueva, 2015, p. 29-48.

ROSENGARTEN, Frank. The Gramsci-Trotsky Question (1922-1932). Social Text, v. 11, p. 65-95, 1984-1985. 
RUIZ SANJUÁN, César. Estado, sociedad civil y hegemonía en el pensamiento político de Gramsci. Revista de Filosofía y Teoría Política, v. 47, p. 1-18, 2016. Disponible en: <http://www.rfytp.fahce.unlp.edu.ar/article/view/RFyTPe002>. Acesso en: 11 nov. 2018.

RUSTIN, Michael. Absolute Voluntarism: Critique of a Post-Marxist Concept of Hegemony. New German Critique, n. 43, p. 146-173, 1988.

SHANDRO, Alan. Lenin and the Logic of Hegemony, Leiden: Brill, 2014.

Texto recebido em 11 de novembro de 2018. Aprovado em 18 de março de 2019. 